\title{
La identidad en los límites del sentido
}

\author{
JuAn PAblo Aranguren Romero*
}

Universidad de los Andes, Bogotá, Colombia

doi: 10.11144/Javeriana.upsy15-2.lils

Para citar esta reseña: Aranguren Romero, J. P. (2016). La identidad en los límites del sentido [Reseña del libro Surviving forced disappearance in Argentina and Uruguay. Identity and meaning]. Universitas Psychologica, 15(2) 21-24. http://dx.doi. org/10.11144/Javeriana.upsy15-2.lils

Profesor del Departamento de Psicología de la Universidad de los Andes, Bogotá, Colombia. Correo electrónico: jp.aranguren@uniandes.edu.co
En Humanitarian Reason. A Moral History of the Present, Didier Fassin (2012) plantea que las situaciones de crisis o catastróficas van aunadas a un conjunto de nociones en torno al sufrimiento y la injusticia, la solidaridad y la compasión; se emparentan con un modo de relacionamiento con la experiencia del otro y se vinculan de diversos modos con sentimientos morales que legitiman los discursos y acciones políticas, trascendiendo la filantropía y enrumbándola hacia el humanitarismo contemporáneo. Como muestra Fassin en otro texto, escrito junto con Richard Rechtman, la sensibilidad moral promovida en un comienzo tras la Segunda Guerra Mundial y luego, con la guerra de Vietnam termina por instalar una particular concepción de la catástrofe, que la ligará, desde entonces, con la de trauma, lo que posibilitará a su vez la emergencia de las nociones de víctima y, por ende, de su estudio, su gestión y administración, es decir, de la victimología (Fassin \& Rechtman, 2009). El vínculo estrecho que se gesta entre catástrofe y trauma delinea una particular forma de relación con el sufrimiento del otro, que permite, en la mayoría de los casos sin pretenderlo, la ontologización del sufrimiento bajo la noción de víctima e incluso, la victimologización de los campos disciplinares y profesionales adscritos a su ayuda, atención o comprensión.

El texto Surviving Forced Disappearance in Argentina and Uruguay. Identity and Meaning de Gabriel Gatti (2014) recorre este lugar ontologizado del trauma en la figura de los familiares de 
desaparecidos en el Cono Sur durante la década de los setenta, y lo cuestiona, mostrando los caminos oscurecidos y entrampados de una identidad provocada por la catástrofe de la desaparición forzada.

El libro, una versión traducida y actualizada de la que el autor presentará con el sello editorial de la uruguaya Trilce bajo el título El detenidodesaparecido: narrativas posibles para una catástrofe de la identidad (2008), analiza en ocho capítulos la catástrofe generada en la identidad y el sentido en la época de la desaparición forzada en Argentina y Uruguay, a partir de una investigación iniciada por Gatti en 2008 que se extendería hasta 2012.

El primer capítulo analiza dicha catástrofe como parte del impulso civilizatorio latinoamericano y de los anhelos por la limpieza, el orden y la belleza y sus consecuentes derivas biopolíticas de disciplinamiento, borramiento, desaparición, silenciamiento y exterminio. En diálogo con los planteamientos de Pilar Calveiro, el autor muestra la forma en la que se emparenta el proyecto civilizatorio y el poder desaparecedor, resaltando que las características de este último no fueron una innovación, ni mucho menos producto de una monstruosidad surgida en las antípodas de la ciudadanía, sino que, como resalta la propia Calveiro "arraigaban profundamente en la sociedad desde el siglo XIX, favoreciendo la desaparición de lo disfuncional, de lo incómodo, de lo conflictivo" (2006, p. 13). A esto Gatti le suma la idea de que, paradójicamente, el poder desaparecedor se ejercerá sobre uno de los productos más preciados del proceso civilizatorio: los ciudadanos de clase media, ilustrados, educados por el mismo sistema que luego los hará de desaparecer. Es para el autor, una suerte de máquina civilizatoria invertida, o acaso, como él mismo lo avizora, el producto exacerbado del proceso de la civilización.

El primer capítulo enmarca así la discusión que se desarrollará en los siguientes cuatro, sobre el proceso civilizatorio que imagina una identidad en la que cuerpo, nombre, filiación de sangre e inscripción comunitaria aparecen unidas, pero que el poder desaparecedor -la modernidad y la civilización exacerbadas- se encargará de fracturar. Se trata de una escisión que recorre (aparentemente con comodidad) los límites del sentido; es la que separa la identidad del cuerpo. Y a lo sumo, se trata de la misma lógica (iracional?) que genera cuerpos sin identidades (como en el caso de los $\mathrm{N}$. $\mathrm{N}$.) o que pretende convertir las identidades, con sus convicciones y solidaridades, en meros cuerpos sufrientes (como en la tortura). Así, bajo este marco se desarrollan los capítulos 2, 3 y 4 que se inscriben en lo que el autor denomina como las narrativas de sentido, es decir aquellas que reconocen en la situación catastrófica la posibilidad de la reconstrucción y la reparación. En el capítulo 2, el autor analiza a los activistas del sentido que intentan dar orden a las ruinas de la catástrofe: archiveros y terapeutas son considerados como la evidencia de un intento por restituir el sentido de la desaparición forzada a partir de huellas que de repente, emergen de lo ignoto para hacer decible lo innombrable. El capítulo tres, profundiza en el intento de los antropólogos forenses de re-hacer y re-unir la escisión catastrófica: unir al cuerpo y al sujeto, vincular la identidad con el nombre. Y el capítulo cuatro, se concentra en las organizaciones de derechos humanos, en particular en «Abuelas de Plaza de Mayo» entendidas como preservadoras del sentido o, como lo desarrollará con lucidez Michael Pollak, como emprendedoras de la memoria (Pollak, 2006). Gatti profundiza en el análisis de la afirmación de los lazos de sangre que en el reclamo por la recuperación de los nietos, termina por afianzar un cierto determinismo biológico que se desliza, para el autor, hacia un cierto conservadurismo identitario, basado en los principios de filiación de la modernidad.

Mientras los capítulos 2, 3 y 4, se acercan a las narrativas de sentido, inscritas tanto en las lógicas administrativas de la catástrofe (los derechos humanos, el humanitarismo y los escenarios transicionales) como en sus dispositivos mandatorios: la memoria, la reparación y la preservación, los capítulos 5, 6 y 7 se acercan a las narrativas de ausencia de sentido, es decir, aquellas que, de cierto modo, muestran la habitabilidad de la catástrofe. Así, mientras en las narrativas del sentido hay un intento de normalización, cierre y renganche civilizatorio, y que en su profundización no deja de mostrarse como una re-afirmación de la pérdida del sentido que generó la maquinaria desaparecedora, 
en las narrativas de ausencia de sentido hay más bien enunciaciones que trasiegan las fronteras de la solidez de la modernidad y que hacen del sinsentido su identidad. El libro profundiza, de esta forma, en la ausencia de sentido que emerge en el acto de retorcer la palabra y de mostrar el vacío y la ausencia, sin llenarlos ni gestionarlos como algo por completar. Al mismo tiempo, amplifica el ruido de los silencios de los ex-detenidos-desaparecidos como una forma de enunciación que cuestiona la pasión por la representatividad y emblematicidad del testimonio. Y, además, muestra en qué medida se pueden construir lenguajes paródicos que, como en el caso de Los Rubios de Albertina Carri (2003), impugnan las memorias institucionalizadas, al narrar la imposibilidad del recuerdo de sus padres desaparecidos.

El libro, cierra con un capítulo dedicado a la transnacionalización de la figura del detenidodesaparecido que contiene diez proposiciones y un análisis acerca de la manera como circula esta figura en los ámbitos de la justicia transnacional y transicional, que reinscribe su lugar en el humanitarismo global.

El libro de Gatti anuncia, pues, que la catástrofe construye mundos, identidades y lenguajes y se convierte en un lugar-el del vacío y la ausencia-donde es posible la vida y no solo el trauma, y muestra que la ruptura de sentido y el quiebre de la identidad trascurre del lado de los azares, las incertidumbres y las ambivalencias presentes no solo en la experiencia de la desaparición forzada, sino en la vida cotidiana de todos los seres humanos ¿Por qué buscar entonces con pasión la identidad íntegra, completa y cerrada?, ¿Por qué anhelar un lenguaje que encaje tramo a tramo con este ideal identitario?

\section{Referencias}

Calveiro, P. (2006). Poder y desaparición. Buenos Aires: Colihue.

Carri, A. (2003). Los Rubios. Film. Buenos Aires.

Fassin, D. (2012). Humanitarian reason: A moral history of the present. Berkeley, Los Ángeles, Londres: University of California Press.

Fassin, D., \& Rechtman, R. (2009). The empire of trauma: An inquiry into the condition of victimhood. Princeton: Princeton University Press.

Gatti, G. (2008). El detenido-desaparecido: narrativas posibles para una catástrofe de la identidad. Montevideo: Trilce.

Gatti, G. (2014). Surviving forced disappearance in Argentina and Uruguay. Identity and meaning. Nueva York: Palgrave Macmillan.

Pollak, M. (2006). Memoria, olvido silencio. La producción social de identidades frente a situaciones límite. La Plata: Al Margen. 
